\title{
Well-being in the Kindergarten Eating Environment and the Role of Early Childhood Educators
}

\author{
Japji Anna Bas
}

Japji Anna Bas is a PhD candidate in the Faculty of Environmental Studies at York University. She is a research and policy analyst with an interest in food policy, school food, international development and environmental politics. Her research explores the ways that public policy shapes social environments and thereby impacts personal well-being. Email: japjiannabas@gmail.com

In Ontario, kindergarten children have recently begun to eat lunch at school with the implementation of the full-day kindergarten program. To date, there are no regulations to address the particular needs of young children in the school eating environment. Drawing on a year-long three-phase study that followed a cohort of 21 children as they transitioned from full-day childcare to full-day kindergarten, this study explores the impact of staff training and staff relationships on the well-being of kindergarten students. Findings suggest that the presence of an early childhood educator (ECE), a minimum staffing of two adults per room, and a collaborative approach between teacher and ECE have a positive impact on child well-being.

Key words: full-day kindergarten; early childhood education; well-being; eating environments
The full-day kindergarten (FDK) program in Ontario was implemented gradually over a five-year period beginning in the 2010-2011 school year and reaching completion the 2014-2015 school year. Prior to FDK implementation, 3 - to 5-year-olds in full-day childcare in Ontario would have been covered under Ontario's Day Nurseries Act (DNA). First implemented in 1948, Ontario's DNA was Canada's first provincial legislation specifically intended for child care. While the DNA was still in effect the year this study was completed, 2014-2015, it has since been replaced by the Child Care and Early Years Act (CCEYA), which has incorporated all previous nutrition-related policy and has added regulations to accommodate allergies, special dietary needs, and special feeding arrangements, along with "Eating Well with Canada's Food Guide-First Nations, Inuit, and Métis" (Health Canada, 2010). The Act integrates an understanding of children's developmental needs into the regulatory system, and has refined age-specific criteria in all relevant areas, including eating and nutrition. By contrast, there are no age-specific regulations whatsoever for food and nutrition in the Ministry of Education's school food and beverage policy.

During the initial years of the FDK program, parents and teachers in the Toronto District School Board (TDSB) reported a number of distressing cases of inappropriately structured eating environments for very young children. In one of the motivating cases for this study, Red Mulberry School ${ }^{1}$, which implemented FDK in year 3 of the rollout (2012-2013), had 100 to 120 junior and senior kindergarten students aged 3-5 years eat lunch in one room under the supervision of only five untrained adults. These children had 20 minutes to eat lunches, often in packaging that the youngest could not even open, in a very loud and chaotic room. Some children could cope, while others simply did not eat, hid under tables, "acted out," or were sent to the office for, for example, hiding under the lunchroom tables (personal communication with JB2 ${ }^{2}$, November 22, 2014; AS, December 1, 2014; MAB, April 13, 2015; CB, February 22, 2017). Teachers reported that many children were "difficult to handle" in the afternoon (MR, personal communication, April 24, 2015) and parents expressed concern for their children's wellbeing during lunchtime (personal communication with DK, November 17, 2014; JB, November 22, 2014; AS, December 1, 2014; MAB April 13, 2015). It was this case, along with other similar accounts, that provided the initial stimulus for this study. 


\section{Method}

This study is a qualitative research study using a mixed methods approach to assess the impact of kindergarten eating environments on children's well-being. Research directly with child participants was based on the mosaic approach (Clark \& Moss, 2001) to facilitate a participatory process. Specifically, the participants introduced the researcher to their space and the people in the room, engaged in multiple loosely structured interviews, defined the meaning of the faces on the well-being chart ${ }^{3}$ used in the study, and drew pictures of their experiences of eating in the various study settings. ${ }^{4}$ These findings were triangulated with field notes detailing participants' activities, attentiveness, and apparent mood throughout the day, supported by commentary from the immediate staff describing, for example, whether the classroom dynamics on a given day were typical or atypical, and interviews with key informants. ${ }^{5}$

Conducted in the fifth year of the FDK rollout, 2014-2015, initial site selection was guided by a range of publicly available data in an effort to consider sites that were as structurally similar as possible. The criteria were as follows: the school was within a particular geographic area bounded by postal code, the school had to have a city-run childcare centre eligible for Toronto Children's Services subsidy, the quality ranking of the childcare centres' preschool rooms were all moderately high, the schools' Fraser Report rankings and learning opportunities index (LOI) were relatively similar, and average parental incomes at all schools in the first round of review were not more than $\$ 5000$ over the poverty line for a family of four. All 17 childcare-school pairings that met the first two criteria were considered. Within this set, four childcare-school pairings met all five criteria. Two of these four childcare centres agreed to participate. The director of the third childcare centre was enthusiastic, but their supervisor declined participation for reasons not made clear to the director. Both the director and supervisor of the fourth childcare centre were enthusiastic, but further investigation revealed a potential conflict of interest. At that time, the supervisor offered that another of the childcare centres they supervised would be able to participate. This centre met four of the five criteria, but exceeded the average parental income stipulated in during the first review. Nonetheless, this site was included to facilitate triangulation of results across the three sites (see Table 1).

Table 1: Site Criteria (2014 Data)

\begin{tabular}{lcccc}
\hline Site & $\begin{array}{c}\text { "Preschool Room } \\
\text { Daycare Quality } \\
\text { Rating"(City of } \\
\text { Toronto) }\end{array}$ & $\begin{array}{c}\text { "School Ranking" } \\
\text { (Fraser Institute) }\end{array}$ & $\begin{array}{c}\text { "Learning } \\
\text { Opportunities } \\
\text { Index"(TDSB) }\end{array}$ & $\begin{array}{c}\text { "Average parental } \\
\text { income" at school } \\
\text { (Fraser Institute) }\end{array}$ \\
\hline Blueberry & $3.51 / 5$ & $7 / 10$ & 224 & $\$ 41,000$ \\
Raspberry & $3.78 / 5$ & $7.2 / 10$ & 324 & $\$ 53,400$ \\
Huckleberry & $3.68 / 5$ & $7.2 / 10$ & 394 & $\$ 72,000$
\end{tabular}

Within each site, only children attending the childcare centre on a full-time basis and intending to attend the FDK program at the same school were eligible to participate. Participation rates were $72.72 \%, 62.5 \%$, and $100 \%$ of eligible children at the Blueberry, Raspberry, and Huckleberry sites respectively, for a total of 20 participants at the inception of the study. Over the course of the study, one child declined verbal assent, one child switched schools, one was not available for the third phase, and another, who intended to change schools but returned, contributed to participant interview data, such that ultimately there were a total of 21 participants -17 for the full course of the study and 4 who participated in one or two thirds of it.

The study was conducted in three phases. In Phase I, through the spring and summer of 2014, full-day observations 
of each participant were taken in the childcare setting with detailed note taking for 5 of every 15 minutes. In addition, participants were asked to situate themselves on an age-appropriate well-being chart consisting of 5 faces once every 90 minutes (with the exclusion of during the scheduled afternoon nap), were invited to draw a picture relating to eating at child care and engaged in a short semistructured interview at the end of the day to discuss their experiences of eating in the childcare centre and at home, along with other areas of interest to the child. During Phase I, the parents of child participants were asked to complete a short survey including both demographic information mirroring that available in school board statistics about the school and questions regarding the child's eating habits. In Phase II, child participants were interviewed twice-once in September and once in October 2014-about their experience of transitioning to kindergarten and were asked to situate their eating experiences on the well-being chart used in Phase I. These interviews were conducted in the after-care setting which, for many participants, was also their daytime classroom. Phase III, much like Phase I, consisted of a full day of observations for each participant, this time in the classroom setting. Between January and June of 2015, child participants were observed for one day each and were interviewed as they situated themselves on the well-being chart once every 90 minutes on their observation day. Additionally, 18 key informant interviews (see Table 2) helped to provide further context and analysis.

\section{Table 2: Key Informant Interviews}

\begin{tabular}{|c|c|}
\hline Name* & Role \\
\hline Kerry McCuaig & $\begin{array}{l}\text { Early childhood policy fellow at the Atkinson Centre for Child } \\
\text { Development, OISE }\end{array}$ \\
\hline Fidelia Torres & $\begin{array}{l}\text { Instructor at the School of Early Childhood Education, George } \\
\text { Brown College }\end{array}$ \\
\hline Beverley Crossdale & Early childhood consultant with Community Living Toronto \\
\hline $\mathrm{R}$ & In-house cook at Raspberry Childcare Centre \\
\hline $\mathrm{E}$ & $\begin{array}{l}\text { ECE at Raspberry Childcare Centre and before- and af- } \\
\text { ter-school program }\end{array}$ \\
\hline CB & Lunchroom supervisor at Red Mulberry School \\
\hline MS & $\begin{array}{l}\text { OISE student teacher at Blueberry School and former ECE with } \\
\text { kindergarten-aged children prior to FDK }\end{array}$ \\
\hline $\mathrm{EC}$ & TDSB kindergarten teacher and former ECE \\
\hline DK & $\begin{array}{l}\text { TDSB kindergarten teacher and parent of child at Red Mulberry } \\
\text { School }\end{array}$ \\
\hline MR & TDSB kindergarten teacher at Red Mulberry School \\
\hline IC & TDSB kindergarten teacher at Huckleberry School \\
\hline
\end{tabular}




\begin{tabular}{|l|l|}
\hline MD & TDSB kindergarten teacher \\
\hline MRB & TDSB kindergarten teacher at Raspberry School \\
\hline GT & Health and physical education teacher at Raspberry School \\
\hline JB & $\begin{array}{l}\text { TDSB special needs teacher; parent of allergenic child at Red } \\
\text { Mulberry School }\end{array}$ \\
\hline AS & $\begin{array}{l}\text { Parent of children at Red Mulberry School, moved to Raspberry } \\
\text { School }\end{array}$ \\
\hline MAB & \begin{tabular}{l} 
Parent of children at Red Mulberry School \\
\hline JJ
\end{tabular} \\
\hline
\end{tabular}

${ }^{*}$ Note: Only the names of interviewees whose work is in the public domain are included. All other names have been altered to protect the anonymity of the children they work with.

The study explores the impact of the lack of age-specific school food policy on the well-being of the participants. Well-being, here, is evaluated according to a model for well-being developed primarily based on Amartya Sen's capabilities approach ${ }^{6}$ (1999), Diener and Seligman's work on well-being (2004), and Martin Seligman's work on flourishing 8 (2011). My model for well-being offers three domains-material security, engagement, and relationship - with meaning at the core, underlying each domain (see Figure 1). ${ }^{9}$

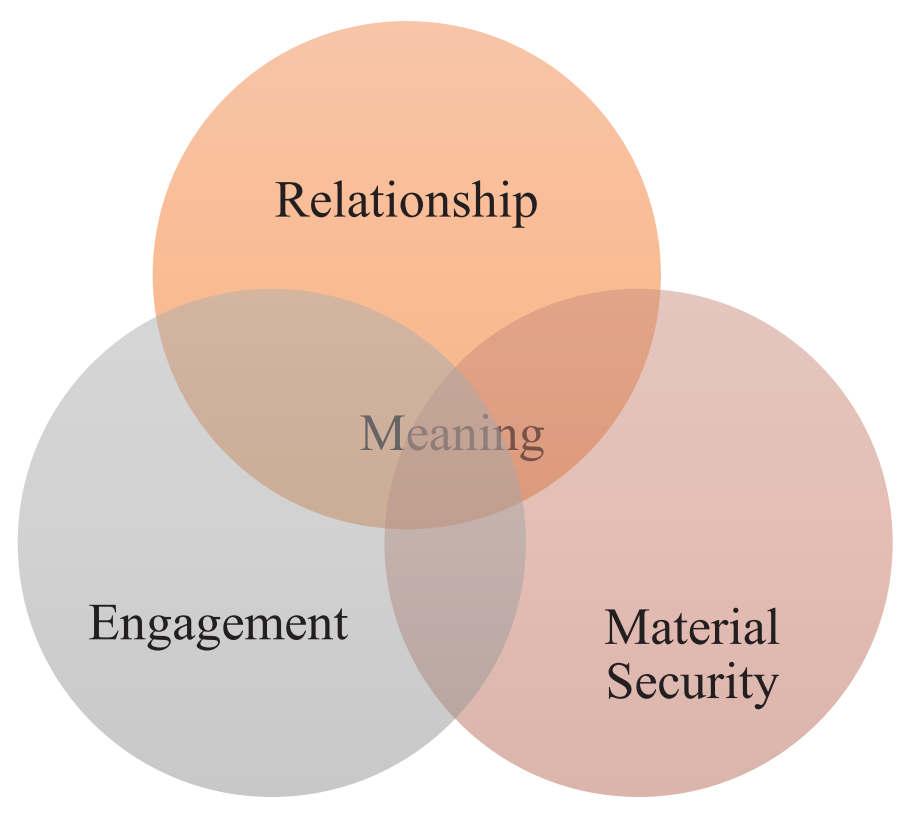

Figure 1: Well-being model. 
These domains align easily with existing assessment categories for school food (Brown, Beardslee, \& ProthrowStith, 2008), Konu and Rimpela's (2002) conceptual model for well-being in schools, and the Ontario Ministry of Education's (2011) student well-being research framework, rendering research findings readily available for both practical and academic applications (see Table 3).

Table 3: Well-being Model and Existing Assessment Categories for School Food

\begin{tabular}{|c|c|c|c|}
\hline $\begin{array}{l}\text { My model for } \\
\text { well-being }\end{array}$ & $\begin{array}{l}\text { Assessment categories } \\
\text { for school food }\end{array}$ & $\begin{array}{l}\text { Conceptual model for } \\
\text { well-being in schools }\end{array}$ & $\begin{array}{l}\text { Student well-being } \\
\text { research framework }\end{array}$ \\
\hline Material security & Health related benefits & $\begin{array}{c}\text { School conditions \& } \\
\text { health }\end{array}$ & Physical \\
\hline Engagement & $\begin{array}{c}\text { Cognitive and educational } \\
\text { benefits }\end{array}$ & Means for self-fulfillment & Cognitive \\
\hline Relationship & $\begin{array}{c}\text { Behaviour and psychoso- } \\
\text { cial benefits }\end{array}$ & Social relationships & Psychosocial \\
\hline
\end{tabular}

This article focuses primarily on the relationship domain in Phase III, specifically exploring how staff training and staffing relationships in the school and school eating environment impact classroom dynamics and children's experiences of their eating environments. ${ }^{10}$

\section{In the Classroom}

As originally proposed in Our Best Future (Pascal, 2009) and elaborated in the Early Years Study 3 (McCain, Mustard, \& McCuaig, 2011) the full-day program would seamlessly integrate teachers and early childhood educators (ECEs) throughout a community hub where children would "spend their day in a consistent environment, with the same adults, all with the same expectations" (p. 10). In Ontario, the FDK program was deliberately structured with intended complementarity in the roles of the classroom teacher and ECE, wherein the former brings knowledge of elementary curriculum and the latter brings knowledge of early childhood development (Underwood et al., 2016). However, implementation has not lived up to this standard and, in the TDSB in particular, the structure of contracts and union relationships has, in many cases, relegated ECEs to a secondary status which, in turn, has excluded them from contributing to planning and class design (K. McCuaig, personal communication, May 6, 2015; Langford et al., 2016). At the same time, this study reveals that some individual school principals who have recognized the value of ECEs and their developmental education skills have managed to cultivate a collaborative atmosphere between classroom teachers and classroom ECEs. Regardless of class size or other factors, in this study, it was those classes in which the teacher and ECE work together to plan and structure both the day and the classroom that functioned the most smoothly, pointing to the central role of the ECE for the well-being of the children in this study.

The study involved childcare-centre-school pairings at Blueberry, Raspberry, and Huckleberry schools, with participants in two classrooms at Blueberry School, three classrooms at Raspberry school, and three classrooms at Huckleberry school (see Table 4). 
Table 4: Participant Distribution in Kindergarten Classrooms

\begin{tabular}{|c|c|c|c|c|}
\hline Site & Classroom & \# of students & $\begin{array}{l}\text { \# of full-study } \\
\text { participants }\end{array}$ & $\begin{array}{l}\text { Lunchtime super- } \\
\text { vision }\end{array}$ \\
\hline Blueberry & East & 26 & 4 & Untrained \\
\hline Blueberry & West & 24 & 3 & Untrained \\
\hline Raspberry & North-East & 33 & 2 & ECE \\
\hline Raspberry & North-West & 33 & 1 & Untrained \\
\hline Raspberry & South-West & 32 & 1 & $\begin{array}{l}\text { Untrained } \\
\text { ECE }\left(B \& A^{*}\right)\end{array}$ \\
\hline Huckleberry & North & 28 & 1 & $\begin{array}{l}\text { + classroom ECE } \\
\text { and teacher }\end{array}$ \\
\hline Huckleberry & East & 28 & 1 & $\begin{array}{l}\text { ECE (B\&A) } \\
+ \text { classroom ECE } \\
1^{\text {st**}^{* *}} \text { ECE (practi- } \\
\text { cum incomplete) }\end{array}$ \\
\hline Huckleberry & North-West & 14 & 4 & $\begin{array}{l}2^{\text {nd }}: \text { classroom } \\
\text { teacher } \\
3^{\text {rd }} \& 4^{\text {th }}: \text { untrained }\end{array}$ \\
\hline
\end{tabular}

At Raspberry School, the principal helped to foster a solid collaborative approach between the teachers and classroom ECEs and, despite having by far the largest classes in the study, these were the smoothest running classes in the study. Classroom ECEs were observed having opportunities to lead activities, classroom teachers were observed collaborating on in-the-moment decision making, teachers described how implementing ECE strategies at snack time, for example, had been effective, and both teachers and ECEs were observed working with the students in small groups.

In contrast, at Blueberry School, the ECEs functioned as teacher assistants. One of the two classes functioned fairly smoothly when the student teacher was present as a contributing member of the teaching team. This student teacher was a former ECE who had worked full-time with preschool- and kindergarten-aged children in a Toronto childcare centre. Unlike the classroom ECE, the student teacher was given opportunities to guide the classroom and, in fact, was observed to engage a participant who appeared disinterested in teacher-led activities. The student teacher attributed the ability to engage the children to previous ECE training (MS, personal communication, March 5, 2015).

In the other class at Blueberry School, the presence of a strong teacher was often insufficient to keep the class engaged, and during centre time many of the typically popular stations-like the water table, science centre, and crafts table-remained entirely vacant while the students' attention was drawn to the Promethean board, an interactive white board which showed children's music videos and cartoons. At one point the teacher had given a participant a "double time out" for reasons he could not recall. The participant described feeling "super sad." In this class, too, the classroom ECE functioned as a teacher's assistant, setting up materials but not contributing to decision making or meaningful opportunities to engage with the students as a group. 
The importance of the ECE was, perhaps, never more evident than in the one classroom in the study with no ECE. At Huckleberry School, four participants were in a class with only 14 students, one teacher, and no ECE. This was the smallest classroom in the most affluent of the three schools, and it was also by far the most chaotic classroom in the study. On observation days, the three male participants in this classroom each initiated two to four violent interactions with their peers every hour and were described as "behavioural" by both the classroom teacher and other teachers, like the drama and library teachers. Because there was only one trained adult in this classroom, the teacher spent large portions of her time managing the particular needs of these students. Though she did employ a range of techniques in her attempts to engage the students, such as starting each day outdoors all year long, teaching lessons outdoors, offering leadership roles, incorporating games like Simon Says into routines, and using both breath work and visualization mindfulness practices, each of these children was sent to the office at least once during observation.

It is worth noting, however, that none of the three boys described as behavioural by the school staff had demonstrated a similar level of aggression in the childcare setting. During Phase I, one of the boys demonstrated deep sadness over separation from family members, sometimes crying throughout the day, consoled only by the close nurturing of one of the ECEs, and another cried easily and often throughout all phases of the study, showing a profound emotional concern for the natural world and animals. While both of these children were observed to be frequently physically violent and threatening to their peers in the school setting, neither one of these children had engaged in a single violent altercation during observation days in the childcare setting just a few months earlier. The third of these boys had demonstrated aggression in the childcare setting, but it was sufficiently infrequent that it did not receive special attention. The FDK program is meant to provide students with fluidity of care in an educational setting where the teacher offers curriculum and the ECE offers "age-appropriate program planning that promotes each child's physical, cognitive, language, emotional, social and creative development and well-being" (Ontario Ministry of Education, 2010). The stark contrast in the "behaviours" of these three children suggests that the absence of an ECE to support emotional and social well-being may have a more significant impact on some children than on others.

The other two classrooms at Huckleberry School, each double the number of students (28 students), were staffed with both a teacher and an ECE. In the east classroom, the ECE was observed tending to a participant's wound from a fall in the playground, spending well over 10 minutes with him to ensure that he felt better both physically and emotionally before he returned to play with his peers. This same ECE was later observed to advocate for children during gym class, engaging a male participant when he was reluctant to participate and advocating for other students when the physical education teacher denied them water and washroom breaks. In the north classroom, the ECE was observed helping the students and the supply teacher follow classroom routines on a day when the regular classroom teacher was involved in a training program. In fact, on multiple occasions, this ECE soothed distraught children and helped the supply teacher better understand the needs of the particular group of children in the class.

Full-day observations, included in the study to gain a better understanding of participants throughout the day when they were hungry, eating, sated, or otherwise, revealed the essential role of ECEs for child well-being in fullday care settings. In classrooms where the ECE played an active role in planning and structure at both Raspberry and Huckleberry Schools, children engaged in activities and were well supported when they could not. In the one classroom observed where the ECE was employed as a support staff, at Blueberry School, centre time appeared dominated by screen time rather than experiential learning, and a participant described receiving a punishment to which he could not ascribe meaning. Finally, in the one class with no ECE whatsoever, three of the four participants demonstrated ongoing signs of distress and exhibited a level of violence inconsistent with their behaviour in the 
childcare setting. The full-day observations within the classroom setting revealed both the ECEs' unique ability to promote the children's overall well-being and the importance of having two trained adults who are familiar with the children present at all times.

\section{The Lunch Hour}

During the lunch hour at school, there are no minimum training requirements for staff. Key informants noted that because lunchtime is not instructional time, it was sometimes viewed as an "afterthought" because "it's only an hour" (personal communication, MD, October 29, 2015; AS, December 1, 2015; CB, February 22, 2017). Additionally, because it is "just an hour" in the middle of the day, the lunch hour can be very difficult to staff (MD, personal communication, October 29, 2015). This, however, is a significant departure from what was intended by the architects of FDK. Indeed, the policy recommendations for staffing clearly outline that "the schedules of the (two classroom) ECEs should overlap during the children's lunch period to allow for lunch breaks for the staff while maintaining a learning environment for the children" (Pascal, 2009, p. 61). Far from an afterthought not included in instructional time, lunchtime in the FDK program was meant to be supported entirely by trained staff to support the children's well-being and mealtime socialization.

In the childcare setting, current regulations require that staffing ratios are 1 staff member for every 8 children, with a maximum of 16 children per room in a preschool room (children ages 2.5 to 6 years) and 1 to 13 with a maximum of 26 children in a kindergarten room ${ }^{11}$ (children ages 3.5 to 5.5 years). During Phase I, study participants were in preschool rooms at their respective childcare centres with a 1:8 staffing ratio and a maximum of 16 children. At Blueberry Childcare Centre, attending staff sat and ate with children at two U-shaped tables while other staff brought food into the room. While staff "sequenced" the food, serving a course of vegetables first, followed by a course that included starch, a protein, and finally fresh fruit at the end, children were offered choice, had the opportunity to serve themselves, and engaged in conversation with their peers. Staff offered guidance, such as reminders to ask to pass dishes rather than reach across the table. Child participants unanimously reported feeling "super-happy" during lunch, and parents reported that their children ate a wider variety of "healthy" foods than they did at home. Similarly, at Raspberry Childcare Centre, staff who were not the attending staff brought the food to the room while children sat at two rectangular tables, each with an attending staff member standing nearby, serving food, and reminding the children to eat. Child participants at this site reported feeling "in the middle," "happy," and "super happy" during lunch. At Huckleberry Childcare Centre, staff were responsible for final-stage food preparation and, as a result, primarily interacted with the children to serve food and to separate "disruptive" children when necessary. In this setting, child participants reported feeling "angry," "nothing," and "super happy" during lunch. Phase I findings suggest that, within the childcare setting, child participants most enjoyed the opportunity to share a meal with staff while being offered both choice and guidance, as was the case at Blueberry Childcare Centre.

In the school setting, in the absence of guiding policy, lunchrooms of up to 33 children were staffed by a single adult. In some cases, the lunch supervisor was an ECE and in others, lunch hour staff were untrained adults. During Phase III, the setting was so often a loud and chaotic one in which the children had difficulty eating and where disruptions and altercations sometimes became violent that the question of optimal eating environment, so present in Phase I, was superseded by the questions "Are the children able to eat?" and "Are the children safe?"

At Raspberry School, one of the lunchrooms was supervised by a trained ECE who was also a staff member in the before- and after-school care program provided by the childcare centre on site. Though this ECE described challenges due to being the only staff member and because the children only had about 20 minutes for the lunch 
portion of the hour, the room she supervised was without incident on observation days. The ECE explained that there had been a steep learning curve in the fall for both herself and the students. However, as she got to know the children, she was able to implement her training to establishing seating arrangements which paired children who had an easy time with the routine with those who did not, focusing guidance on those children who had the most difficulty or were the most likely to disrupt their peers, structuring calm activities for those children who tended to eat very quickly (so that those who were still eating were not drawn to play in lieu of eating), arriving early to structure toileting time, and maintaining an even and instructive tone during emergent incidents. The child participants in this room reported feeling "in the middle" and "sad" during lunch, though within the context of other kindergarten lunchrooms observed, it is noteworthy that children were both safe and able to eat.

On the other hand, the other two classrooms were supervised at lunch by untrained adults. In one case, the lunch supervisor (LS) was the parent of a child at the school, and in the other case, the LS was the grandparent of a student at the school. The former LS explained that, feeling very overwhelmed at the start of the school year, she had independently undertaken to read as much as she could about child development of 3-to 5-year-olds and strategies for "managing" classroom dynamics. Of the lunchrooms supervised by untrained adults, this was the most effective insofar as while the room was messy and loud, the children were safe. That said, the LS was observed to manage the lunchroom in this way at the expense of assisting opening containers and offering children guidance-the room was not dangerous, but the children did receive the adult attention they required. The LS in the other room was both kind and hardworking, but during observation the lunchroom descended into chaos when one child had a toileting accident in the washroom requiring the full attention of the one staff present. Over a short period of time, mounting numbers of children became distressed at not being able to use the rest room. At the same time, two separate altercations among a total of five students distracted other students, most of whom were then unable to eat. The one participant in the room joined a group of her peers rearranging the furniture, dragging the children who were still eating around the room in their chairs. The participant in this room reported feeling "super happy" and appeared more energetic than she did at any other time that day, perhaps indicating a need for more unstructured play time. That said, she ate less than a quarter of her lunch. In fact, few children ate that day and, later, the classroom ECE noted that the children were "always more hungry for afternoon snack," while, in classrooms where the lunchroom environment was conducive to the children eating lunch, few children participated in afternoon snack.

Neither of the two kindergarten classes at Blueberry School had trained staff supervising the lunch hour. In one class, the lunchroom was supervised by a parent of a child at the school, and the other class was supervised by someone who lived nearby. In addition, both rooms had students from older grades in the kindergarten lunchrooms who were meant to assist the younger children. In the east classroom, supervised by a parent, there were no significant safety issues, but the majority of the children were not able to eat even half of their lunch during the allotted time frame, and child participants reported negative feelings about this. In fact, while this was not among the most challenging lunchrooms in the study, the LS in this room engaged me in a lengthy conversation, eager to express concern over the functioning of the lunchroom, centered around the belief that "it is essential that there be better staff-to-student ratios during the lunch hour." In this room, the older children sat together in a corner of the room and were of no assistance whatsoever. While there were no noteworthy safety concerns, students' inability to eat enough food during the allotted time is problematic.

The LS in the other lunchroom was not able to effectively communicate with students because of limited English skills and instead spent the time in the lunchroom cleaning. Based on observations, it seems that the staff at the school was aware of this situation and made efforts to supplement the formal supervision, though there was no verbal confirmation of this. On observation days, both the classroom teacher and the classroom ECE were 
observed giving up their own lunch break to assist in supervision. Another teacher from the school came to relieve the classroom teaching staff on two separate occasions. Additionally, the school principal spent part of the lunchtime with this classroom on each observation day. When asked, child participants reported that these adults were in the classroom at lunchtime "always," "mostly always," "most of the time," and "it's always like this." The older students in this classroom actively engaged the kindergarten students, though this engagement seemed to increase in the presence of the principal and classroom teacher. All of this suggests that the school staff were working together to manage what appeared to be a suboptimal staffing arrangement. Unfortunately, even with this level of oversight, the classroom LS offered me chocolates with nuts on three separate occasions in a school with a kindergarten student having an anaphylactic nut allergy. The seriousness of this failing cannot be overstated, especially because it is part of the lunchroom supervisor's job to ensure adherence to the TDSB's "peanut-free zones" policy when there are children with severe allergies present.

At Huckleberry School, both of the classrooms with only one participant were supervised at lunch by an ECE, whereas the small class with four participants was supervised for the first six months by a supervisor who had completed the ECE program coursework but had not yet completed the practicum and for the last four months by an untrained adult. In the north classroom, both the classroom ECE and the classroom teacher joined the LS ECE to ensure that the students had a strong team and continuity during the lunch hour. This was by far the best-staffed room in the study, as the LS ECE was also a staff member in the before- and after-school care program run by the childcare centre in the building and the teacher was sufficiently dedicated to even donate her time on a day when she was engaged in training elsewhere in the building. The "seamless care" approach was seen in action here, and the lunch hour in this classroom was relaxed and comfortable, though this came at the expense of both members of the teaching team donating their lunch break to the students. The other kindergarten classroom which was also staffed with an ECE-trained lunchroom supervisor (who was also a staff member in the before and after school care program) and the donated time of the classroom ECE, was similarly calm and without incident, as compared to the lunchrooms with untrained staff.

Again, the one class of only 14 students offers an interesting case because it was the only lunchroom in which the same students were observed with both (partially) trained and untrained staff. There was one observation day in February, while the trained LS was still in place. On this day, while there were significant challenges during the regular class hours, the lunchtime ran smoothly. The LS explained that initially, "lunch was crazy. I can't explain it, it was just crazy." The LS went on, however, to explain that they had established a seating arrangement (with as few as two students to a table and none of the challenging students seated together) and a handwashing and washroom routine that staggered the children based on each child's pacing, as observed. The LS described that "it took about a month and a half to get it sorted" (personal communication, February 11, 2015). On that observation day, there were no incidents during the lunch hour and, in fact, the lunchtime was calmer than it had been during instructional time and offered students a relaxed eating environment.

The observation days when the lunchroom was supervised by an untrained adult show a different picture. On one of the three other observation days, two of the challenging students were absent and the LS was late enough that lunch was almost entirely supervised by the classroom teacher. While this lunch hour was relatively smooth, the classroom teacher described that day as atypical, repeatedly telling me, "it's so quiet today because two of the major players aren't here. This never happens!” (personal communication, May19, 2015). According to the classroom teacher, the relative calm could be attributed to the absence of two of the "disruptive" children, though lunch had also been quite calm in the presence of an ECE-trained lunch supervisor. The lunch hours on the other two observation days were described as typical for that room and were both consistent with the classroom challenges and with the other lunchrooms supervised by untrained adults. In other words, there was an escalation 
of disruptive and dangerous behaviour during the lunch hour. For example, on one day a male participant aggressively chased a female student around the room, and when he caught her, he pulled her to the ground by the back of the neck, mounted her, and searched her pockets. He explained later that he believed she had stolen candy from his backpack. This was not the only violent altercation this student initiated during the 20-minute lunchtime supervised by an untrained adult, but it was the only one the lone staff member observed. On the other observation day, the participant being observed had a very difficult time coping in the absence of a familiar adult. Though he was slightly less aggressive with his peers than he had been during instructional time, he did not eat anything at all, he knocked other children's food to the ground, he knocked down the building structure a peer had left to work on after lunch, and he cried deeply and could not be consoled by the lunch supervisor. It was clearly an extremely difficult 20 minutes for this child. The lunch hour findings from a typical day in this atypical classroom support the findings from the other lunchrooms in the study: that kindergarten children require support from familiar trained staff during the lunch hour.

Overall, regardless of class size or the typical functioning of the students in the classroom, those lunchrooms supervised by a trained ECE functioned much better than those supervised by an untrained adult. That said, it is imperative to note that every ECE-trained lunchroom supervisor underscored that the lunchrooms are severely understaffed, based on the needs of children aged 3 to 5 years old. The lunchroom ECE at Raspberry School elaborated that they were unable to properly implement their training due to excessive numbers of children in a small space, inadequate staff-to-student ratios, and insufficient time for children to eat (personal communication, January 29, 2015). Nonetheless, when compared to lunchrooms supervised by entirely untrained staff, ECEs were at least able to create a safe environment in which the children could at least eat. There is a structural suboptimality to lunchtime, which the ECEs are able to partially mitigate, but this by no means represents a best practice.

Child participants, at the age of 3 or 4, were understandably unaware of the staff's level of training and, additionally, had no basis for comparison. With respect to the kindergarten eating environment, the children did, however, independently ${ }^{12}$, repeatedly, and consistently note that (1) there was not enough time to eat, (2) they were reprimanded for talking, and (3) it was often too noisy to eat. Nonetheless, most participants still felt positively about lunch because (1) they liked to eat, and (2) they liked being able to talk to their friends. The fact that the children both complained about being reprimanded for talking with their peers and pointed to talking with peers as one of the reasons they like lunchtime indicates that offering a lunch setting where they have the time to eat and socialize would be appreciated by children of this age. Indeed, it is noteworthy that children independently identified the lost opportunity for socializing as a concern and the possibility for socializing as an asset, because key informant interviews also identified the lost opportunity for mealtime socialization as one of the problems with the school eating environment.

\section{Setting the Tone}

Both the nature of the relationship between the teacher and the ECE in the classroom and the structure of the lunchroom setting are significantly impacted by the direction set by the principal. According to the literature, the principal is the single most important factor in school effectiveness (Bartoletti \& Connelly, 2013; Smith, 2016). Additionally, key informant interviewees underscored the central role of the principal (personal communication, MRB, June 25, 2015; GT, June 25, 2015; E, June 23, 2015) and suggested that principals have considerable leeway in structuring both the budget and the timetable for staff, with considerable direct impact on the classroom environment (personal communication, LB, April 27, 2015; MD, October 2015; JB, November 22, 2015), thereby establishing the parameters of staffing and staff-to-student relationships (personal communication, LB, April 27, 2015; MD, October 2015; AS, December 1, 2015 ). As the librarian at Blueberry School noted, "the whole 
school culture reflects the principal's leadership" (personal communication, April 27, 2015). This is consistent with observations throughout the study. While this is a qualitative study with a small sample size, because there were participants in multiple classrooms at each school it was possible to gain a sense of what kind of teacher-ECE relationship each of the three principals fostered. Children benefitted from the input of the classroom ECE in those settings where a balanced teacher-ECE relationship was fostered. This finding is consistent with the literature (Corter et.al. 2007; Gibson \& Pelletier, 2010; McGinty, Justice, \& Rimm-Kaufman, 2008).

Throughout the course of the study, key informants described the benefits of the fluid care model, and one key actor described how this model was implemented during the lunch hour at their school. Kerry McCuaig, Fidelia Torres, and the student teacher and former kindergarten-age ECE all echoed the importance of seamless transitions and fluid care that were outlined in Pascal's (2009) With Our Best Future in Mind (personal communication, K. McCuaig, May 6, 2015; F. Torres, June 18, 2015; MS, March 5, 2015). The student teacher explained that during their years as an ECE, the staff closely monitored what children ate (as is required by regulation) and would gain a sense of "how they [the children] would be able to manage in the afternoon" (personal communication, MS, March 5, 2015). Through developing close relationships with the children and always having a trained staff person well known to each child in the room, the staff in the childcare centres could better anticipate and respond to the children's needs. Another key informant, a kindergarten teacher whose assignment was to be the relief staff for all five kindergarten teachers at their school, described a solution to the lunchroom staffing challenge employed at their school. Based on concerns about the safety of the children during the lunch hour, the kindergarten teachers at their informal weekly lunch hour meetings came up with a proposal that classroom teacher and ECE lunch breaks be staggered so that every day, every kindergarten lunchroom would be staffed by both a lunch supervisor and one member of the regular classroom teaching team. The principal agreed, and the teaching staff reported that the situation had "improved" (MD, personal communication, October 29, 2015). This third-party report suggests that kindergarten students at this school benefitted from the principal's willingness to implement this teacher-driven strategy.

That said, this is but a single case within a much larger system. Additionally, whether assessing the impact of principals, teachers, ECEs, or lunchroom supervisors, it is important to bear in mind that great people can sometimes transcend structural weaknesses. Consequently, it is important not to conflate the efficacy of an extraordinary individual working in a poorly designed system with programmatic success. Indeed, the goal here is to identify the problem areas and best practices in order to benefit all students. One challenge, as both the teacher from the small classroom at Huckleberry School and the teacher from the aforementioned example have noted, is that parents remain unaware of what the problem areas are, and consequently cannot contribute to dialogue advocating for programmatic change. Indeed, one parent of a child participant described enquiring about the lunch hour, finding staff responses evasive, and feeling that "the whole thing is shrouded in mystery" (personal communication, $\mathrm{BMP}$, October 2014). What is frightening, is that this secrecy may be intentional. One interviewee, a kindergarten teacher in the TDSB, described someone from the Ontario Ministry of Education Early Years Branch specifically instructing the kindergarten teaching staff at their school to "not be too specific" in response to parent concerns about the lunch hour, explaining that "we want this to sound good." The interviewee when on to say "Why don't the parents know? Because the school knows it's bad.... I don't think it's okay. I want parents to understand that it is hard to keep them [the children] safe with these parameters" (MD, personal communication, October 29, 2015). These sentiments - that it is up to the parents to lobby for change, on the one hand, and that parents are kept, or are intentionally kept, in the dark, on the other-echo throughout the key informant interviews. It is clear is that there is a need for both further research and greater transparency in order to have a meaningful dialogue and establish best practices for the kindergarten eating environment. 


\section{Conclusion}

The study was initially designed to examine the well-being impacts of the kindergarten school eating environment and to identify best practices for age-specific regulation in this area. The childcare setting offers a useful basis for comparison, because children of this age have been in full-day care in childcare centres for decades, often in school buildings, and the regulation of this care is mandated through the Ministry of Education. Among the three sites, Blueberry Childcare Centre offered the eating environment with the highest approval rating among child participants and the most positive impact on both mealtime socialization and food choices, based on study observations and parent reports. The structure of the school lunch hour, with expectations that children will eat and play outdoors in one hour under the supervision of single, often untrained, adult, raised questions of basic safety and whether or not the children were able to eat. Excluding rooms where staff donated their time out of concern for the children, the best kindergarten lunchroom in the study was the one at Raspberry School staffed by a single ECE. This room, however, can be described as effective but not optimal, because while the children were safe and could eat, the lunchroom operated with an institutional efficiency and child participants expressed negative feelings about this.

Throughout the first and third phases of the study, participants were observed for a full day. Classroom observations demonstrated that the most effective classrooms were those staffed by two adults, a teacher and an ECE, who had the opportunity to cultivate a collaborative approach to running the classroom. While in these cases the collaborative approach was supported by a strong principal, this needs to be supported through policy, as was intended by the architects of FDK (Pascal, 2009). Both key informants and the literature suggest that structuring planning time for both members of the teaching team promotes co-teaching (K. McCuaig, personal communication, May 6, 2015; Underwood et. al., 2016).

Furthermore, study findings suggest that best practices in eating environments were only found in the childcare setting, that the safest school lunchrooms are staffed by trained ECEs, and that some lunchrooms staffed by untrained adults can only be described as dangerous. In fact, teaching staff, ECEs, and untrained lunchroom staff all expressed concern for the welfare and well-being of children during the lunch hour under the current conditions. Observations show that many staff members are sufficiently concerned about lunchroom staffing that they volunteer their time to support their students during that time, in some cases even in the presence of an ECEtrained lunchroom supervisor. The rooms in which ECE lunchtime supervision is supplemented with classroom ECE and/or teacher supervision represent the closest example of a best practice in the school setting and most closely align with the original design for FDK. While it is clear that the students in these classes benefit from this volunteer work, the risks evident in some of the classrooms demonstrate that a policy response is necessary to ensure better supervision and care during the lunch hour for all students.

\section{References}

Bartoletti, J., \& Connelly, G. (2013). Leadership matters: What the research says about the importance of principal leadership. National Association of Elementary School Principals. Retrieved from https://www.scribd.com/document/218001537/leadershipmatters

Brown, J. L., Beardslee, W. H., \& Prothrow-Stith, D. (2008). Impact of school breakfast on children's health and learning. Commissioned by the Sodexo Foundation.

Clark, A., \& Moss, P. (2001). Listening to young children: The mosaic approach. Wiltshire, UK: National Children's Bureau \& Joseph Rowntree Foundation.

Corter, C., Bertrand, J., Pelletier, J., Griffin, T., McKay, D., Patel, S., \& Ioannone, P. (2007). Toronto First Duty phase 1 final report: Evidencebased understanding of integrated foundations for early childhood. Toronto, ON: Toronto First Duty. 
Diener, E., \& Seligman, M. (2004). Beyond money: Toward an economy of well-being. Psychological Science in the Public Interest, 5(1), $1-31$.

Gibson, A., \& Pelletier, J. (2010). Can we work together? Preliminary findings from an examination of ECE and teacher dynamics in full-day early learning-kindergarten. Retrieved from https://www.oise.utoronto.ca/atkinson/UserFiles/File/Events/2011-06-01\%20-\%20 Summer\%20Institute/SI2011_Poster_ECEandKteacher.pdf

Health Canada. (2010). Eating well with Canada's food guide: First Nations, Inuit, and Métis. Retrieved from https://www.canada.ca/en/ health-canada/services/food-nutrition/reports-publications/eating-well-canada-food-guide-first-nations-inuit-metis.html

Konu, A., \& Rimpela, M. (2002). Well-being in schools: A conceptual model. Health Promotion International, 17(1), $79-87$.

Langford, R., Di Santo, A., Valeo, A., Underwood, K., \& Lenis, A. (2016). The innovation of Ontario's full-day kindergarten teams: Have they reproduced the split systems of care and education? Gender and Education, 1-18.

McCain, M. N., Mustard, J. F., \& McCuaig, K. (2011). Early Years Study 3: Making decisions, Taking action. Toronto, ON: Margaret \& Wallace McCain Family Foundation.

McGinty, A. S., Justice, L., \& Rimm-Kaufman, S. E. (2008). Sense of school community for preschool teachers serving at-risk children. Early Education and Development, 19(2), 361-384.

Ontario Ministry of Education. (2010). The full-day early learning kindergarten program (draft version). Retrieved from https://www.edu. gov.on.ca/eng/curriculum/elementary/kindergarten_english_june3.pdf

Ontario Ministry of Education. (2011). Student well-being research framework. Retrieved from http://www.tcdsb.org/Board/Documents/ Student\%20Well-Being\%20Research\%20Framework.pdf

Pascal, C. (2009). With our best future in mind: Implementing early learning in Ontario. Toronto, ON: Queen's Printers of Ontario.

Seligman, M. E. P. (2011). Flourish: A visionary new understanding of happiness and well-being. New York, NY: Free Press.

Sen, A. (1999). Development as freedom. New York, NY: Anchor Books.

Smith, B. (2016). The role of leadership style in creating a great school. Retrieved from https://selu.usask.ca/documents/research-andpublications/srrj/SRRJ-1-1-Smith.pdf

Underwood, K., Di Santo, A., Valeo, A., \& Langford, R. (2016). Partnerships in full-day kindergarten classrooms: Early childhood educators and kindergarten teachers working together. Canadian Children, 41(4), 36-45.

\section{(Endnotes)}

1 Site names have been changed to protect the anonymity of the children.

2 With the exception of three professionals in the field of early childhood whose views are in the public domain, anonymity was offered to all key informants to protect the privacy of the children they work with.

3 The well-being chart used in this study included 5 faces including super happy/WB5, happy/WB4, neutral/WB3, sad/WB2 and super sad/WB1. The neutral face was referred to as "kind of in the middle" and some participants referred to it as "bored". Additionally, some participants identified WB1 as "angry". 
4 The initial study design included children taking photographs, as in the original mosaic study, but the ethics research review committee at the school board declined the use of photography.

5 Staff commentary during observation days was documented in field notes, whereas key informant interviews were recorded and were not conducted on site.

6 In Development as Freedom (1999), Nobel laureate Amartya Sen builds on Aristotle's understanding of human flourishing, arguing that "development has to be more concerned with enhancing the lives we lead and the freedoms we enjoy" (p. 14). Sen outlines that an emphasis on human capability, rather than human capital, leads to "the expansion of human freedom to live the kind of lives that people have reason to value" (p. 295). Ultimately Sen posits that a person's ability to lead a good life is based on valued beings and doings, such as being healthy and having loving relationships, and this capabilities approach contributes to a new set of social indicators, including the United Nations Human Development Index which embodies this approach to well-being.

$7 \quad$ Similarly, in "Beyond Money: Toward an Economy of Well-Being" (2004), Diener and Seligman argue that "well-being should become a primary focus of policy makers" because, once basic needs are met, social relationships and work satisfaction emerge as key indicators for well-being, which, in turn, produces positive outcomes like improved work performance and good health.

8 More recently, in Flourish: A Visionary New Understanding of Happiness and Well-Being (2011), Seligman outlines five elements of well-being-positive emotion, engagement, relationship, meaning, and accomplishment (pp. 13-29).

9 Because my model is eudaimonic (focusing on meaning and self-realization to evaluate functioning), not hedonic (focusing on feeling pleasure), positive emotion, or affect, is not among the domains.

10 The comparison of children's eating experiences in the childcare setting and the kindergarten setting is addressed in an article in review for Social Indicators Research and overall policy recommendations are detailed in an article in review for Canadian Association of Food Studies.

11 Preschool room regulations under the Child Care and Early Years Act remain the same as they were under the Day Nurseries Act (in its final year at the time of the study), though kindergarten room regulations have gone from a ratio of 1:10 with a maximum of 20 children to $1: 13$ with a maximum of 26 children. 
12 In response to general questions, such as "How do you feel about lunch at school?" children identified these areas of concern without prompting or suggestion in conversation with the reviewer. 